\title{
Comparison of different methods to determine the anaerobic threshold of transfemoral amputees using prosthesis
}

\begin{abstract}
Introduction: Transfemoral amputation causes cardiopulmonary, muscular and biomechanical changes that affect the physiology of physical exercise. The anaerobic threshold is one of the main indicators of the cardiopulmonary test (CPET), since it is the determinant of the balance between production and lactate removal, that is, the maximum intensity of exercise, thus determining the physical performance and ventilatory performance. The present study aims to analyze the Anaerobic Threshold (LA) of transfemoral amputees under different methods of analysis.
\end{abstract}

Methodology: CPET was performed in seven unilateral transfemoral amputees using prosthesis (age 30 years \pm 4.89 ). The tests were performed in a cycle ergometer, with ramp protocol with effort measurement by the Borg Subjective Perceive Perception Scale, using the Vmax ergospirometer (CareFusion). The descriptive analysis of the data was performed by SPSS software.

Results: The methods of visual graphical analysis and the method of automatic linear ventilation presented similar values in relation to the ventilatory variables, and the mathematical model and the visual graph obtained similar measures in the respiratory and cardiovascular aspects, determining the LA almost at the same time, being the Transfemoral amputee threshold is lower than predicted for age group.

Conclusion: Thus, it is confirmed that the methods of graphical visual analysis and the heteroscedastic mathematical model are presented as gold standard for determination of LA, due to its sensitivity and reliability. Therefore, further studies on the determination of the anaerobic threshold in transfemoral amputees are required in order to compare with the findings in this study.

Keywords: amputation, anaerobic threshold, mathematical model, physiotherapy
Volume I Issue $3-2017$

\author{
Bruna da Silva Sousa,' Thanyze Alice Vicentini \\ Zoccoli,' Gabriela Ataides de Oliveira,' \\ Lourdes Mattos Brasil, ${ }^{2}$ Vera Regina \\ Fernandes da Silva Marães ${ }^{3}$ \\ 'Department of Biomedical Engineering, University of Brasília, \\ Brazil \\ 2Department of the Clinical Engineering, University of Brasília, \\ Brazil \\ ${ }^{3}$ Department of the Physiotherapy Course, University of Brasília, \\ Brazil
}

Correspondence: Bruna da Silva Sousa, Department of Biomedical Engineering, University of Brasília, Brazil, Email bruzinhadolly27@gmail.com

Received: May 26, 2017 | Published: June 29, 2017
Abbreviations: CPET, cardiopulmonary exercise test; FCS, faculty of health; TCLE, term of free and informed consent; IPAQ, international questionnaire of physical activity

\section{Introduction}

Transfemoral amputation is a withdrawal of the limb with a cut-off level between the disarticulation of the knee and the hip joint ${ }^{1}$ and lower limb amputations cause structural, mechanical and metabolic changes, these changes being forms of adaptation to new body condition. ${ }^{2}$ Some metabolic alterations are more scientifically investigated due to their physiological impact, such as metabolic expenditure (use of energy to perform activities or exercise work), oxygen consumption and anaerobic and aerobic thresholds, considering that these variables undergo general and specific modifications, being related to the use of auxiliary mechanisms, prostheses and their compositions. It is known that transfemoral amputees present the need to adapt to their new life condition, and the auxiliary devices require physical effort and increase in ventilation to perform their daily activities, which causes an increase in consumption and oxygen uptake, anaerobic threshold, heart rate, in order to maintain the static and dynamic balance. ${ }^{3,4}$ When performing physical exercise, the human body makes changes in different body systems, being these: cardiovascular, hormonal, sanguineous, respiratory and skeletal muscle.,
The anaerobic threshold or anaerobic threshold (LA) is the determinant of the balance between lactate production and removal, i.e., the maximum intensity of exercise. Currently, this threshold has been increasingly studied to determine physical perfomance and ventilatory performance, since it presents the peak moment of the glycolytic pathway that causes alterations in the production of lactic acid, considering that studies of VO2 max are showing more and more inconsistency for the quantification of aerobic capacity, being gold standard only for aerobic power.

In view of the greater consistency of information obtained through the anaerobic threshold, this has been used not only in scientific articles, but also for measurement Of physical performance, in order to compare according to the age group; For the creation of protocols of physical training and treatment for determination of loads that do not promote risk stress to the cardiovascular system; And to diagnose diseases, in view of the demonstration of failures or absence of oxygen supply. ${ }^{8,9}$

The LA has a direct interaction with the cardiovascular and respiratory systems, since, when reaching the maximum level of lactate accumulation and intensity in the metabolic and In the musculature, the activity of the autonomic nervous system increases significantly amplifying the parasympathetic and mainly, the sympathetic discharges, in which increases the capitation of oxygen 
and carbon dioxide, alteration in the walls of veins and arteries, increasing contractions of the heart and Changes in ejection volumes and ventilatory capacities. ${ }^{10}$ Thus, through the Cardiopulmonary Exercise Test (CPET) or Ergospirometry, it is possible to verify the cardiovascular, respiratory, skeletal muscle, neurological, humoral and hematological variables. Through the analysis of gas exchange during physical exertion, aerobic and anaerobic thresholds and oxygen consumption allow the physiotherapist and other health professionals to identify the level of activity of the respiratory and cardiovascular systems. This level of cardiorespiratory activity consequently affects the muscular system and biomechanics of the amputee. Therefore, the TECP is a valuable tool for the physiotherapist to perform a functional evaluation and determine measures to reduce metabolic expenditure and propose/prescribe modifications in the uses of auxiliary devices and components of prostheses.

Over the years, different methods of determination of the anaerobic threshold using the variables offered by the TECP were described in the literature, being presented the mathematical models with greater efficiency to determine the LA. However, the most used methods are those of graphic visual analysis and linear analysis, due to its ease of application, in which, for the population of the present research, there is a shortage of studies on the determination of LA. ${ }^{11}$ The present study aims to determine the anaerobic threshold of transfemoral amputees by ventilatory (visual visual), ventilatory (linear automatic), and heteroscedastic mathematical model by means of heart rate. And, thus, compare the threshold observed in the three methods and correlate to the values of power and heart rate.

\section{Methodology}

The cross-sectional observational study was submitted and approved by the Ethics Committee of the Faculty of Health Sciences (FCS) of the University of Brasilia (UnB) (11911/12). Volunteers were informed about the research and its possible risks, as well as those who agreed with it, signed the Term of Free and Informed Consent (TCLE). All of them were recruited through the Training Center of Special Physical Education of the Federal District (CETEFE-DF) and the Nucleus of Production of Orthosis and Prosthesis of the Federal District (NPOP-DF).

Participated in this study volunteers who met the following criteria Of inclusion: men aged between 18 and 45 years, regular physical activity (at least 3 times a week), unilaterally proteased amputees, exclusion criteria being carriers of cardiovascular, circulatory, respiratory diseases, hormonal and/or metabolic disorders, Smoking, frequent alcohol use, drug users or regular medications that could influence cardiorespiratory responses. The volunteers were classified qualitatively on the level of physical activity, through the International Questionnaire of Physical Activity (IPAQ), in its short version. The questionnaire had questions about perception the intensity, durability and frequency of physical activities, with three individuals classified as "very active" and four as "active".

The cycle ergometer (Corival Quinton Equipamentos Ltda ${ }^{\circledR}$ ) With ramp protocol was used to perform the cardiopulmonary tests, depending on the patient conditioning predicted by the IPAQ, with an increase of 10,15 or $20 \mathrm{~W} / \mathrm{min}$, in order to determine the functional capacity and Anaerobic capacity, with effort measurement by the Subjective Perception Perception Scale of Borg (BORG), using the ergospirometer Vmax (CareFusion ${ }^{\circledR}$ ) and electrocardiograph (Cardiosoft $\left.{ }^{\circledR}\right)$. To perform the tests, the environment was temperature controlled $\left(18-22^{\circ} \mathrm{C}\right)$, with the presence of two physiotherapists and a cardiologist, maintaining verbal stimulation. The durability of the test was determined by the level of physical exertion, muscle and/or respiratory fatigue, disembedding of the prosthesis, signs of cardiac events and/or changes in the electrocardiogram.

\section{Statistical analysis}

The descriptive analysis of the data was performed by the Statistical Package for Social Sciences (SPSS) ${ }^{11}$ software using arithmetic mean and standard deviation, analyzing the statistical difference through the Friedman test for multiple sample comparisons and the Spearman correlation test, So that statistically significant differences presented confidence interval values $>95 \%, r \geq 1.0, p \leq 0.05 .^{12}$

\section{Methods of analysis for the determination of the anaerobiosis threshold}

\section{Graphic visual ventilatory method (MVG)}

The visual ventilatory method Graph is one of the most described and used methods in the literature, which is the analysis of the variables $\mathrm{VO} 2$ and $\mathrm{VCO} 2$ obtained with each breath, as a function of the time of exercise in seconds arranged in the graph created by the examiner. This method is considered as gold standard, since it allows the observation of the moment of loss of linearity of the variables, that is, the expression of the $\mathrm{VCO} 2$ curve is superior to that of $\mathrm{VO} 2 .^{13,14}$

In this way, the examiner was previously trained by means of a theoretical/practical course of realization and analysis, in order to extract the data of the respiration-breathing platform of the ergometer Vmax (Carefusion ${ }^{\circledR}$ ) as PDF file (Adobe Acrobat Document ${ }^{\circledR}$, Windows 10) and perform the plotting for the EXCEL software (Windows-10), whereby, manually, it would move the LA demarcation course by the graph until the moment of loss of linearity. The Figure 1 represents the ventilatory variables $\mathrm{VO} 2$ and $\mathrm{VCO} 2$ obtained breathto-breath, as a function of time expressed in seconds, with manual graphical analysis performed by the visual visual method.

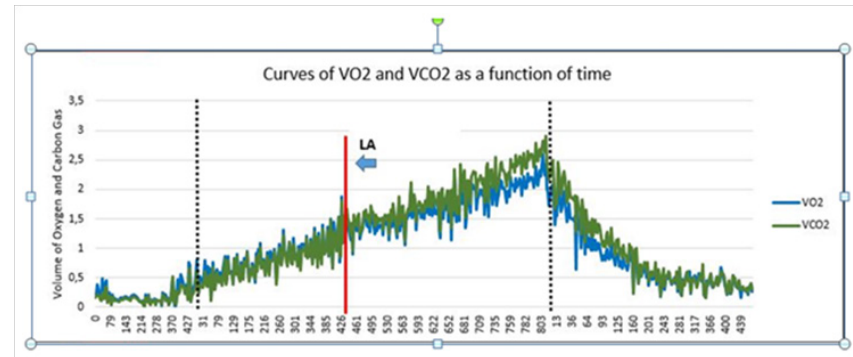

Figure I Volume of oxygen and carbon dioxide volume, obtained with each breath as a function of time (sec), so that the black lines delimit exercise time, with manual graphical analysis of one of the volunteers.

\section{Automatic linear ventilatory method (MVA)}

The linear ventilatory method treats the search for the loss of linearity between the $\mathrm{VO} 2$ and $\mathrm{VCO} 2$ curves from a command in the EXCEL software (Windows-10). The control performed maintains three consecutive values of carbon dioxide volume increase in comparison to the oxygen volume as a function of time in seconds, and when this value is obtained, the software demarcates the result in the constructed graph. This command was adapted to Excel, resembling the automatic determination of software such as MedGraphics, since 
they use the same loss of linearities and calculations of macros. ${ }^{14}$ The Figure 2 represents the ventilatory variables $\mathrm{VO} 2$ and $\mathrm{VCO} 2$ obtained from respiration to respiration, as a function of the exercise time expressed in seconds, with analysis using the automatic linear ventilatory method.

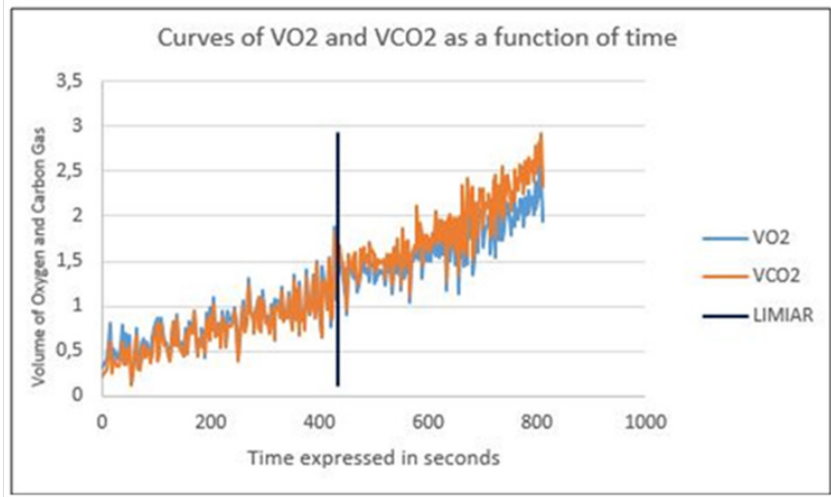

Figure 2 Oxygen volume and carbon dioxide volume, obtained with each breath as a function of exercise time $(\mathrm{sec})$, with automatic graphical linear analysis of one of the volunteers.

\section{Heteroscedastic mathematical model (MH)}

The heteroscedastic mathematical model is described as a simple linear segmented regression model, in which the function presents a dependent and an independent variable, so that according to time, random errors are calculated for estimation Of coefficients that will trace a graphic illustration of the moment when the heart rate expressed in bpm as a function of time presents its point of change. ${ }^{15}$ For this, a linear regression was sought in the literature that most resembled the data studied. In this way, specific commands for the data studied were created using Matlab 8.3, 2014 (Mathworks, Natick ${ }^{\circledR}$ ) software, which determined the threshold point by means of the frequency point Cardiac. The Figure 3 shows the heart rate in beats per minute, as a function of the exercise time expressed in seconds, through the analysis of the heteroscedastic mathematical method, created by MATLAB software.

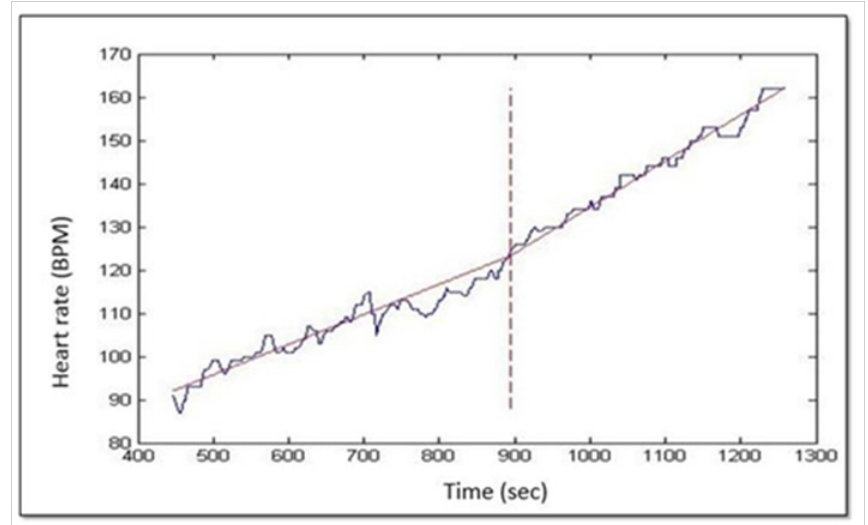

Figure 3 Heart rate expressed in beats per minute, as a function of Total time of the cardiopulmonary test $(\mathrm{sec})$, with analysis by heteroscedastic mathematical method of one of the volunteers.

\section{Results}

Seven male transfemoral amputees under prosthesis were studied. With a mean age of 30 years ( \pm 4.89 Standard Deviation), mean height of 1.78 meters $( \pm 0.03)$, mean body mass index d And $22,54 \mathrm{~kg} /$ $\mathrm{m}^{2}( \pm 3,00)$, mean amputation time of 7.05 years $( \pm 2.06)$ and being classified as active (4 volunteers) and very active (3 volunteers) according to the International Questionnaire Physical Activity IPAQ. ${ }^{16}$ The sub maximal exertion test was obtained in $100 \%$ of the volunteers, and the decoupling of the prosthesis was the major limiting factor of the test, in $87.5 \%$ of the cases; and muscle fatigue in the residual stump was $12.5 \%$. Therefore, it is believed that another type of socket and/or prosthesis would have allowed greater durability of the test. Frame 1 shows the characteristics of the studied sample, taking into account the age, weight and time of amputation.

Frame I Characteristics of the sample. Descriptive anthropometric data of transfemoral amputees(n=7), Ceilândia, 2016.

\begin{tabular}{lll}
\hline Variable & Mean & Standard deviation \\
\hline Height & 1,78 & $\pm 0,03$ \\
Weight & 71,42 & $\pm 8,20$ \\
Age years) & 30,71 & $\pm 4,89$ \\
BMl $\left(\mathrm{kg} / \mathrm{m}^{2}\right)$ & 22,54 & $\pm 3,00$ \\
Amputation time (years) & 7,05 & $\pm 2,06$ \\
\hline
\end{tabular}

Frame 2 Mean values of $\mathrm{VO} 2, \mathrm{VCO} 2, \mathrm{HR}$ and anaerobic threshold power, identified by the visual and automatic linear ventilation methods, heteroscedastic mathematical model. Level of significance of $p<0.05,(n=7)$, Ceilândia, 2015.

\begin{tabular}{llll}
\hline Variables & Graphic method visual $(\mathbf{p} \leq \mathbf{0 , 0 0})$ & Automatic linear method $(\mathbf{p} \leq \mathbf{0 , 0 2})$ & Heteroscedastic model \\
\hline VO2 & $1,183 \pm 0,379$ & $1,076 \pm 0,523$ & $1,120 \pm 0,509$ \\
VCO2 & $1,216 \pm 0,366$ & $1,103 \pm 0,532$ & $1,25 I \pm 0,540$ \\
FC & $\mid 21,7 \pm 15,00$ & $115,2 \pm 15,33$ & $122,42 \pm \mid 7,75$ \\
Potência & $77,57 \pm 31,29$ & $59,85 \pm 40,97$ & $79,57 \pm 33,21$ \\
\hline
\end{tabular}

VO2, Oxygen volume;VCO2, Oxygen consumption; HR, Heart rate; Power. Work done in Watts; $\mathrm{p} \leq 0.05$ 


\section{Discussion}

The protocol used for this study was that of ramp, which is characterized by increasing intensity continuously, with an increase in load, being 10,15 or $20 \mathrm{~W} / \mathrm{min}$, depending on the classification of the individual, according to IPAQ. The ventilatory and cardiac adjustments were performed by the $\mathrm{V}_{\max }$ device (ventilatory variables) and Cardiosoft (cardiovascular variables). This makes it possible to avoid large work overloads that may result in estimates of exercise capacity, lasting between 8 and 12 minutes. The advantage of the protocol used was to provide more accurate measurements of the functional capacity of transfemoral amputees, thus facilitating an individualized evaluation of the cycle ergometer. According to Barros et al. ${ }^{21} \&$ Oliveira et al. ${ }^{22}$ and the Brazilian Society of Cardiology, the expected time for the development of the test is the average of 12 minutes, so that our volunteers reached an average of 10minutes of testing, being considered submaximal because they presented in most cases decoupling of the prosthesis $(87,5 \%)$ and muscle fatigue of the residual stump (12.5\%). It should be noted that, in the literature, there is no ramp protocol for transfemoral amputees.

The main variables obtained are: maximum oxygen volume $\left(\mathrm{VO}_{2}\right)$, effort time, initial and final velocity, initial and final inclination, and type of exercise. These variables were determinant for obtaining the anaerobic threshold, since it is known that the protocol generates a direct impact on the values of $\mathrm{VO}_{2}, \mathrm{VCO}_{2}$ and, consequently, in $\mathrm{HR}^{22}$

In order to compare with the obtained data, On the determination of the anaerobiosis threshold in transfemoral amputees, however, only classic studies on energy expenditure and aerobic capacity were found from maximal oxygen consumption. ${ }^{4,23}$ Due to this limitation, we opted for discussion with evidence of individuals not amputated.

There is a paucity of evidence regarding the determination of $\mathrm{VO}_{2}$ and $\mathrm{VCO}_{2}$ values, during the anaerobic threshold, in transfemoral amputees, mainly in non-invasive methods, such as the cardiopulmonary stress test. Considering that the study population performed regular physical activities, there is the permissibility of comparison with studies on very active individuals.

The study by Leal ${ }^{24}$ compared the anaerobic threshold of athletes soccer and futsal players, demonstrating that futsal athletes reach LA values faster than soccer players, that is, they present lower anaerobic capacity the players that perform less muscle activation And/or requiring less energy expenditure.

When comparing the value obtained in the anaerobic threshold in soccer samples $(3.46 \pm 0.351 / \mathrm{min})$ and futsal $(2.97 \pm 0.441 / \mathrm{min})$ by the graphic visual method with the values obtained, in the same method, For very active and active amputees $(1,183 \pm 0,3791 / \mathrm{min})$, it is observed that the anaerobic capacity of transfemoral amputees was lower in comparison to non-amputated individuals in men's futsal athletes.

Still on the visual method, A study carried out with elderly men who performed regular activities (mean $61.4 \pm 1.78$ years), performed a maximal effort test using the ramp protocol to determine LA and aerobic capacity of the volunteers, and the examiners followed up During the test the same respiratory and cardiovascular variables as the present study. ${ }^{17-24}$

The study presented mean values of $\mathrm{VO}_{2}(12.6 \mathrm{ml} / \mathrm{kg} / \mathrm{min}), \mathrm{HR}$ (99bpm) and Power (71Watts) during LA, so that in transfemoral amputees, the highest HR values $(121.7 \pm 15.00)$, with a mean power (77.57 \pm 31.29 ), thus it is believed that the study population reaches the LA in potencies close to that of healthy elderly people, however, it presents high values of heart rate By mitochondrial and cardiorespiratory adjustments due to loss of limb. ${ }^{14}$

Another study carried out with middle-aged men with arterial hypertension comparing them with healthy men, carried out TCPE through the ramp protocol with a 10 to $15 \mathrm{~W} / \mathrm{min}$ increase in load, Demonstrated that in the MV values of $\mathrm{VCO} 2$ of the hypertensive group presented between (1,000 to 1,2001/min) while the healthy ones presented (500 to $9001 / \mathrm{min}$ ), when analyzing these values presented, it is observed that hypertensive and amputated individuals present greater demand Of gas volume ca Ronic disease in comparison to healthy individuals of the same sex and age..$^{25}$

Studies with different populations comparing the use of the visual and automatic linear ventilatory method confirm greater sensitivity in the graphic visual, being indicated as the gold standard method for LA determination, corroborating with the results presented in the present study, reporting that the measurements made by the MVG and $\mathrm{MH}$ are similar. ${ }^{14,15,26}$

In 2006, a comparative study between the determination of LA by blood levels and the automatic linear ventilatory method in male cyclists (27.88 \pm 8.77 years), showed that the LA moment was similar in both analyzes, showing that the MVA (3.78 \pm 00.41$) 1 / \mathrm{min}$ and HR $(186.63 \pm 10.35 \mathrm{bpm})$. In the present study, the same method obtained lower values of both variables, and the mean age difference was not so much higher than the study of. ${ }^{27}$

Studies with mathematical models to obtain LA are considered bold scientific evidence and of great technological advance, given the difficulty of manipulating data analyzer software. Since the heteroscedastic and Hinkley method are the ones with the greatest description and reproducibility for ventilatory variables and especially heart rate. ${ }^{13,14}$

Increasingly, the heteroscedastic model has been represented In the literature for other studies, being Pozzi ${ }^{14}$ pioneer in the use of simple linear segmented regression applied to heart rate to determine the anaerobic threshold. Lime ${ }^{26}$ the literature review in search of other studies using $\mathrm{MH}$, returning only the classic pioneering study of Pozzi. ${ }^{14}$

The present study demonstrated that the mathematical model presented similar measurement values to the gold standard method, corroborating with the statements of the classic study, suggesting larger studies using different software with regressive commands.

In addition, it is observed that the mathematical model of Hinkley is one of the most described in the literature and presented in the study of ${ }^{14}$ strong correlation with the heteroscedastic method, which reaffirms the sensitivity and reliability of the analysis. The heart rate presented higher values in transfemoral amputees (122.42>105bpm), meanwhile reached lower load compared to active elderly (82 Watts> 79.57). ${ }^{14}$

As studies on heart rate are of extreme importance for the determination of LA, since the elevation of heart rate during exercise is an acute cardiovascular adjustment. The decrease or insufficient elevation of this variable indicates ischemic disease, or morphological alterations in the cardiovascular system. ${ }^{28,29}$ One of the classic studies on the behavior of heart rate during progressive physical exercise 
performed in healthy men during a ergometer test on cycle ergometer showed that heart rate values increased during LA compared to baseline. ${ }^{30-32}$

\section{Conclusion}

The present study, through different forms of determination, was able to measure similar values of anaerobic threshold of transfemoral amputees, allowing the identification of graphical visual methods and heteroscedastic mathematical model as gold standard methods due to high reliability and sensitivity. It is also demonstrated that the anaerobic threshold of transfemoral amputees presents higher values in comparison to healthy sedentary individuals and smaller than active healthy individuals, being necessary new studies with larger samples and with better prosthetic fittings for better quantitative analysis, and finally use of Heteroscedastic mathematical models for quantitative identification proved to be effective.

\section{Acknowledgments}

To the National Council of Scientific and Technological Development (CNPQ) and the Support Foundation of the DF (FAPDF) for the financial support.

\section{Conflict of interest}

The author declares no conflict of interest.

\section{References}

1. Carvalho JA. Amputações de membros inferiores: em busca da plena reabilitação. 2nd ed. São Paulo: Manole; 2003.

2. Pastre CM, Salioni JF, Oliveira AF, et al. Fisioterapia e amputação transtibial. Arq Ciênc Saúde. 2005;12(2):120-124.

3. Fernandes A, Ramos A, Casalis M, et al. AACD: Medicina e Reabilitação Princípios e Prática. s/ed.São Paulo: Artes Médicas Ltd; 2007.

4. Bona R, Aldabe D, Ribeiro J. Avaliação do gasto energético em pacientes amputados de membro inferior protetizados. Arq Sanny Pesq Saúde. 2008;1(2):98-108.

5. Eldridge FL, Millhorn DE, Kiley JP, et al. Stimulation by central command of locomotion, respiration and circulation during exercise Respir Physiol. 1985;59(3):313-337.

6. Jamison JP, Megarry J, Riley M. Exponential protocols for cardiopulmonary exercise testing on treadmill and cycle ergometer. Eur J Appl Physiol. 2010;108(1):167-175.

7. Wasserman K, Mcilroy MB. Detecting the threshold of anaerobic metabolism in cardiac patients during exercise. Am $J$ Cardiol. $1964 ; 14(6): 844-852$.

8. Gallo JL, Maciel BC, Marin NJ, et al. Ajustes cardiovasculares ao exercício físico: efeitos do treinamento aeróbio. Medicina (Ribeirão Preto. Impresso). 1990;23(2):101-106.

9. Sakabe DI. Quantificação do limiar de anaerobiose durante exercício físico dinâmico em homens de meia idade: análise da resposta de variáveis cardiorrespiratórias e musculares. São Carlos. Tese [Mestrado]Universidade Federal de São Carlos, Brazil; 2004.

10. Beaver WL, Wasserman K, Whipp BJ. A new method for detecting anaerobic threshold by gas exchange. J Appl Physiol. 1986;60(6):20202027.

11. Nie NH. SPSS: Statistical Package for the Social Sciences. New York: McGraw-Hill; 1979.
12. Martínez ORM, Tuya PLC, Martínez OM, et al. El coeficiente de correlacion de los rangos de spearman caracterizacion. Rev haban cienc méd. 2009;8(2):2-19.

13. Crescêncio JC. Determinação do limiar de anaerobiose ventilatório no exercício físico dinâmico em indivíduos sadios. Comparação entre métodos obtidos por análise visual e modelos matemáticos. Ribeirão Preto. Tese [Mestrado] - Universidade de São Paulo, Brazil; 2002.

14. Pozzi LG, Melo Rc, Queterio RJ, et al. Determinação do limiar de anaerobiose de idosos saudáveis: comparação entre diferentes métodos. Rev bras fisioter. 2006;10(3):333-338.

15. Vanderlei LCM, Carlos MP, Rosângela AH, et al. Noções básicas de variabilidade da frequência cardíaca e sua aplicabilidade clínica. Rev Bras Cir Cardiovasc. 2009;24(2):205-2017.

16. Benedetti TRB, Antunes PC, Rodriguez-Añez CR, et al. Reprodutibilidade e validade do Questionário Internacional de Atividade Física (IPAQ) em homens idosos. Rev Bras Med Esporte. 2007;13(1):11-16.

17. Lima PAL. Determinação do Limiar Anaeróbio de homens com asma pela variabilidade da frequência cardíaca durante exercício em esteira. Caderno de Graduação-Ciências Biológicas e da Saúde-UNIT. Springer; 2014:11-23.

18. Marães VRFS. Frequência cardíaca e sua variabilidade: análises e aplicações. Revista Andaluza de Medicina del Deporte. 2010;3(1):33-42.

19. Ribeiro TF, Gomes VR, Moura MSA, et al. Estudo do limiar de anaerobiose em mulheres sedentárias durante o esforço físico dinâmico. In: XVII Reunião da federação de sociedades de biologia experimental FESBE, Caxambu: Springers; 1998. 258 p.

20. Ribeiro TF. Avaliação da modulação autonômica da atividade eferente do coração pela variabilidade da freqüência cardíaca em mulheres sedentárias. Mestrado em Fisioterapia, Universidade Federal de São Carlos, Brazil: Springer; 2001.

21. Fritzen LF. Análise cinemática da marcha de amputados transtibiais com diferentes tipos de pés protéticos. Mestrado em bioengenharia, Universidade de São Carlo: Brazil; Springer; 2012.

22. Barros NTL, Tebexreni AS, Tambeiro VL. Aplicações práticas da ergoespirometria no atleta. Rev Soc Cardiol Estado de Säo Paulo. 2001;11(3):695-705.

23. Oliveira BF. Análise comparativa dos resultados obtidos no teste de ergoespirometria em jogadores de futebol de campo das categorias Infantil e Juvenil da Associação Atlética Aciaria Ipatinga-MG. MOVIMENTUMRevista Digital de Educação Física. 2017;2(1):1-11.

24. Bona RL, Aldabe D, Ribeiro JL. Avaliação do gasto energético em pacientes amputados de membro inferior protetizados. Arq Sanny Pesq Saúde. 2005;1(2):98-108.

25. Leal J, Souza FDB, Magini M, et al. Estudo comparativo do consumo de oxigênio e limiar anaeróbio em um teste de esforço progressivo entre atletas profissionais de futebol e futsal. Rev Bras Med Esporte. 2006;12(6):323-326.

26. Sacilotto MC, Grossi RTD, Sirol FN, et al. Relation between heart rate and power at the peak of the ergometric test and anaerobic threshold of healthy and hypertensives in middle-aged men. Fisioterapia em Movimento. 2007;20(4):43-53.

27. Lima CR. Identificação do limiar anaeróbico através da variabilidade da frequência cardíaca durante a realização de exercício progressivo. Universidade Federal de Minas Gerais, Brazil; 2012. p.1-61.

28. Okano AH, Altimari LR, Simões HG, et al. Comparação entre limiar anaeróbio determinado por variáveis ventilatórias e pela resposta do lactato sanguíneo em ciclistas. Rev Bras Med Esporte. 2006;12(1):39-44. 
29. Guyton AC. Fisiologia Humana. Rio de Janeiro Ed. Brazil: Interamericana; 1981.

30. Couto PG, Rodrigues AP, Ferreira AJ, et al. Pontos de transição da frequência cardíaca em teste progressivo máximo. Rio Clar. 2013;19(2):261-268

31. Conconi F, Ferrari M, Ziglio PG, et al. Determination of the anaerobic threshold by a noninvasive field test in runners. $J$ Appl Physio. 1982;52(4):869-873.
32. Marães VR, Teixeira LC, Catai AM, et al. Determinação e validação do limiar de anaerobiose a partir de métodos de análise de frequência cardíaca e de sua variabilidade. Rev Soc Cardiol Estado de São Paulo. 2003;13(4SA):1-16. 